\title{
Avaliação do perfil liquórico de caninos (Canis lupus familiaris) naturalmente infectados com o vírus da cinomose antes e após tratamento com ribavirina (Ribaviron $\mathrm{C}^{\circledR}$ )
}

\section{Cerebrospinal fluid profile of naturally infected dogs with canine distemper virus before and after ribavirin (Ribaviron $\mathrm{C}^{\circledR}$ ) treatment}

\author{
Simone Henriques Mangia, ${ }^{*}$ Jane Megid, ${ }^{* *}$ Anna Paula Vitirito Martinho, ${ }^{* *}$ Rodrigo Garcia Motta, ${ }^{* * *}$ \\ Camila Michele Appolinário, ${ }^{*}$ Eduardo Sotelo Salcedo, ${ }^{* \star *}$ Regina Kiomi Takahira, ${ }^{* * * *}$ Antonio Carlos Paes ${ }^{* *}$
}

\begin{abstract}
Resumo
A cinomose é uma enfermidade infectocontagiosa, importante na população canina, que não possui tratamento antiviral efetivo. A ribavirina é uma droga antiviral inibidora da replicação de alguns vírus e é reconhecida a sua eficácia frente ao vírus da cinomose "in vitro". Foram selecionados dez animais com sinais neurológicos e evolução clínica da enfermidade de até dez dias. Foi colhido o líquor de todos os animais e neste foram avaliadas principalmente as características de celularidade e proteinorraquia. Os animais incluídos na pesquisa receberam ribavirina por via oral, na dose de $30 \mathrm{mg} / \mathrm{kg}$, a cada 24 horas, durante 15 dias. No último dia de tratamento foi realizada nova colheita de líquor. Os parâmetros liquóricos foram avaliados pelo teste de Mc Nemar, para os seguintes achados: pleocitose, número de linfócitos acima de $60 \%$, proteínas acima de $25 \mathrm{mg} / \mathrm{dl}$ e teste de Pandy. Não houve significância estatística entre as alterações da primeira colheita e a segunda. Apenas três animais vieram a óbito, com piora clínica progressiva; outros dois animais não obtiveram melhora aparente, porém sobreviveram ao período de tratamento e os demais apresentaram redução dos sinais. A ribavirina foi capaz de diminuir a gravidade das lesões na maioria dos animais tratados.
\end{abstract}

Palavras-chave: cinomose, tratamento, ribavirina, líquor.

\begin{abstract}
Canine Distemper is an important infecto-contagious disease with no effective antiviral treatment. Ribavirin is an antiviral drug that inhibits some virus replication and well known for its effectiveness against Canine Distemper Virus "in vitro". Ten dogs with neurological signs and 10 days of maximum clinical evolution were selected to the present study. The cerebrospinal fluid was collected from all the animals for protein compounds and cellularity characteristics evaluations. Animals were treated with ribavirin orally, with dose of $30 \mathrm{mg} / \mathrm{kg}$, each 24 hours, for 15 days. On the $15^{\text {th }}$ day of treatment, a second cerebrospinal fluid collection was made and the parameters were evaluated by Mc Nemar test to the following findings: pleocytosis, lymphocytes above $60 \%$, protein up to $25 \mathrm{mg} / \mathrm{dL}$ and Pandy test. No statistical difference was found between the first and second moments. However only three animals died with progressive clinical worsening; other two animals did not show clinical improvement, but survived to the treatment and the other animals presented signs reduction. Ribavirin has proven effectiveness in decreasing the gravity of lesions in majority of treated animals.
\end{abstract}

Keywords: canine distemper, treatment, ribavirin, cerebrospinal fluid.

\section{Introdução}

A cinomose é uma enfermidade infectocontagiosa, causada por um RNA-vírus, da Família Paramyxoviridae, do gênero Morbillivirus, sendo o agente mais importante que acomete a população canina (Corrêa e Corrêa, 1992). Entretanto, acomete animais das famílias Canidae, Mustelidae, Hyaenidae, Procyonidae, Ailuridae, Viverridae, Felidae, Ursidae, Phocidae,
Tayassuidae e Cercopithecidae. A patogenia da infecção pelo vírus da cinomose varia de acordo com a espécie e pode resultar em infecções inaparentes ou causar alta mortalidade (Tipold et al., 1992; Summers et al., 1995; Van Moll et al., 1995; Cho e Park, 2005).

A cinomose possui três formas de apresentação clínica: aguda, subaguda e crônica, com manifestações gastrintéricas,

\footnotetext{
* Programa de Pós-Graduação em Medicina Veterinária (Doutorado) - Departamento de Higiene Veterinária e Saúde Pública, Faculdade de Medicina Veterinária e Zootecnia, UNESP, Campus Botucatu, SP. Rubião Júnior, s/n, Botucatu, SP. CEP 18.618-970. Caixa Postal 560.

** Departamento de Higiene Veterinária e Saúde Pública, Faculdade de Medicina Veterinária e Zootecnia, UNESP, Campus Botucatu, SP.

*** Programa de Pós-Graduação em Medicina Veterinária (Mestrado) - Departamento de Higiene Veterinária e Saúde Pública, Faculdade de Medicina Veterinária e Zootecnia, UNESP, Campus Botucatu, SP.

**** Departamento de Clínica Veterinária, Faculdade de Medicina Veterinária e Zootecnia, UNESP, Campus Botucatu, SP.
} Autor para correspondência: Simone Henriques Mangia. E-mail: simangia@hotmail.com 
respiratórias e neurológicas. São descritas três formas de encefalite causada pelo vírus da cinomose: encefalite dos cães jovens, encefalite em cães adultos e encefalite do cão velho (Corrêa e Corrêa, 1992).

A doença pode acometer caninos de todas as idades, porém existe uma relação entre susceptibilidade e idade. Filhotes com três a seis meses de idade são mais susceptíveis pela diminuição dos anticorpos maternos neste período. O curso clínico e neuropatológico da encefalomielite pode ser determinado pela variedade da cepa viral e a idade do animal (Corrêa e Corrêa, 1992; Summers et al., 1995; Moro e Vasconcelos, 1998; Headley e Graça, 2000; Gebara et al., 2004). Na doença clínica encontram-se as seguintes características: falta de imunização ou doses incompletas, vacinas inapropriadas, colostro da mãe com títulos inadequados de anticorpos, imunossupressão e história de exposição a cães infectados (Greene e Appel, 2006).

A encefalite aguda, que ocorre inicialmente no curso da infecção em animais jovens ou imunossuprimidos, é caracterizada por injúria viral direta às células do sistema nervoso central (CNS). Nesta fase mudanças inflamatórias são mínimas, devido à imunodeficiência resultante da imaturidade do sistema imune e/ ou decorrente da imunossupressão viral induzida (Vandevelde e Zurbriggen, 1995; Gebara et al., 2004; Greene e Appel, 2006).

A encefalite multifocal em cães adultos causada pelo vírus da cinomose aparece frequentemente entre quatro e seis anos, com curso crônico. Esta enfermidade não é precedida nem coincidente com os sinais sistêmicos que são vistos nos cães jovens (Corrêa e Corrêa, 1992) e caracteriza-se por apresentar pouca expressão do antígeno viral e uma resposta imune intensa no SNC, podendo progredir para a doença crônica (Vandevelde e Zurbriggen, 2005; Greene e Appel, 2006).

Para o auxílio no diagnóstico, as características físico-químicas do líquor, tais como coloração, aspecto, densidade, $\mathrm{pH}$ e glicose, não são capazes de contribuir para indicar qualquer anormalidade liquórica, nas diferentes fases da cinomose. Por outro lado, o componente proteico e a celularidade liquórica apresentaram alterações importantes na presença de sinais neurológicos, porém na ausência destes, não adicionam informações capazes de levar a detecção precoce de lesões do SNC em colaboração ao diagnóstico da referida enfermidade (Gama et al., 2005).

O aumento dos anticorpos antivírus no líquor, que pode ser representado pelo aumento da concentração de proteínas acima de $25 \mathrm{mg} / \mathrm{dl}$, oferece uma definitiva evidência da encefalite pela cinomose, porque estes anticorpos são produzidos no local, e este aumento não é encontrado em animais vacinados ou na cinomose sistêmica sem alterações neurológicas (Greene e Appel, 2006).

A falta de tratamento antiviral para a infecção do vírus da cinomose requer tratamento de suporte e sintomático (Tipold et al., 1992). No entanto, a ribavirina vem sendo considerada como fármaco no tratamento da cinomose, após o referido trabalho de Elia et al. (2008), que testou a mesma frente o vírus da cinomose "in vitro". Segundo os autores, a ribavirina causa mutações no vírus da cinomose e estas levam a um erro catastrófico no RNA do genoma viral.

A ribavirina é uma droga antiviral, análoga à guanosina, inibidora da replicação "in vitro" de alguns RNA e DNA-vírus, incluindo Herpesvírus, Poxivírus, Influenza vírus, Parainfluenza vírus, Reovírus, Togavírus, Paramyxovírus e Tumor RNAvírus. "In vivo", o espectro antiviral é menor, com ação contra Herpesvírus, Influenza vírus, Parainfluenza vírus, vírus do Sarampo e Adenovírus (Hayden e Douglas, 1990). No grupo dos Paramyxovirus todos os componentes são sensíveis a ribavirina, sendo o vírus do sarampo o mais sensível (Chang e Heel, 1981).

O atual estudo tem como objetivo avaliar a utilização da ribavirina frente ao vírus da cinomose, em animais naturalmente infectados apresentando sinais clínicos de encefalite, através da análise do líquor.

\section{Materiais e métodos}

Foram selecionados aleatoriamente 10 animais que apresentavam sintomatologia neurológica, com tempo de evolução até 10 dias, independentemente do sexo e raça. Todos os animais apresentavam idade entre dois meses e seis anos. A seleção destes foi realizada no setor de enfermidades infecciosas dos animais, do Hospital Veterinário da Faculdade de Medicina Veterinária e Zootecnia da UNESP / Campus Botucatu, SP.

O estudo está de acordo com os Princípios Éticos na Experimentação Animal e foi aprovado sob o número de protocolo 54/2006-CEEA pela Comissão de Ética no Uso de Animais da Faculdade de Medicina Veterinária e Zootecnia da UNESP / Campus Botucatu, SP.

Para a inclusão dos cães no estudo, os sinais neurológicos deveriam sugerir lesões multifocais, com apresentação clínica compatível de doença inflamatória do SNC, com sinais clínicos agudos e progressivos. Além dos sinais, os animais foram avaliados com relação ao histórico de imunização, o desenvolvimento clínico da doença e o exame físico.

Todos os animais foram anestesiados com o mesmo protocolo, sendo a dose ajustada em relação às condições físicas e de consciência.

A medicação pré-anestésica utilizada foi a associação de acepromazina com o diazepam, a qual foi administrada por via intramuscular, na dose $0,05 \mathrm{mg} / \mathrm{kg} \mathrm{e} 0,2 \mathrm{mg} / \mathrm{kg}$, respectivamente. Após 30 minutos, o tiopental sódico foi administrado por via intravenosa, na dose máxima de $10 \mathrm{mg} / \mathrm{kg}$, com objetivo de obtenção da tranquilização dos animais.

No primeiro momento, durante o atendimento no hospital, foi colhido sangue total por meio da punção da veia jugular, com seringas e agulhas descartáveis, para a realização do esfregaço sanguíneo utilizado na reação de imunofluorescência direta para detecção do vírus da cinomose.

Para obtenção do líquor foi utilizado o procedimento descrito por Ducoté e Dewey (2006), que relata a retirada, de uma só vez, de $1 \mathrm{~mL}$ de líquor para cada $5 \mathrm{~kg}$ de peso corporal. No atual estudo estimamos até 20 gotas de líquor por animal, dependendo do peso. O material foi colhido em tubo de vidro esterilizado, sem adição de anticoagulantes.

O líquor foi obtido da cisterna cerebelomedular e para tal o animal foi posicionado em decúbito lateral e o pescoço flexionado, com o nariz mantido paralelo à mesa. No local da punção, realizaram-se tricotomia e assepsia da pele e foi introduzida uma agulha hipodérmica descartável e estéril na linha média da articulação, direcionada para o espaço atlantoccipital. $O$ fluido foi obtido por gotejamento e dividido no momento da 
colheita em três tubos, para evitar contaminação pelo sangue periférico durante o procedimento. Utilizou-se o terceiro tubo para a análise citológica.

A colheita de líquor foi realizada no momento em que o animal chegou ao Hospital Veterinário e após 15 dias de tratamento com ribavirina.

A técnica de reação de imunofluorescência direta foi realizada com amostras de sangue de todos os animais. Para esta forma de diagnóstico foi necessário $1 \mathrm{~mL}$ de sangue periférico, colhido em seringas agulhadas estéreis e imediatamente realizadas as lâminas de esfregaço sanguíneo.

Após a realização de esfregaço sanguíneo, a lâmina ficou 30 minutos em temperatura ambiente até a secagem completa. Em seguida, foi realizada a fixação do material com solução de acetona e metanol, na proporção de 75:25 imerso por 30 minutos. Após retirar da solução, foram confeccionados poços de aproximadamente $5 \mathrm{~mm}$ de diâmetro com esmalte, onde foram colocados $50 \mu \mathrm{L}$ de conjugado puro. A lâmina, já com o conjugado, foi incubada em câmara úmida a $37^{\circ} \mathrm{C}$ por uma hora. Após retirar da câmara úmida, a lâmina foi lavada cuidadosamente em solução salina tamponada $8,5 \%$ durante três minutos, sendo repetidas três vezes, e uma última lavagem rápida com água destilada. A lâmina foi montada com uma gota de glicerina tamponada em cada poço e lamínula por cima. A leitura foi realizada em microscópio de fluorescência em aumento de 400X.

Devido à rápida lise celular no ambiente de baixa concentração proteica do líquor, a contagem de células e as avaliações citológicas do fluido foram realizadas dentro de 30 a 60 minutos após a colheita.

As análises de rotina realizadas incluem avaliação física, química, quantitativa (contagem de hemácias e células nucleadas) e microscópica (observação dos padrões celulares).

Foram avaliados o volume, cor, aspecto, densidade e a presença de coágulos na amostra. O líquor normal é claro, transparente, incolor e incoagulável (Ducoté e Dewey, 2006). As alterações registradas como partes do exame físico foram classificadas como discretas, moderadas ou intensas. A mensuração da densidade (ou gravidade específica) foi realizada com uso do refratômetro.

O exame químico do líquor foi realizado com tiras reagentes (Combur Test ${ }^{\circledR}$ ) e foram avaliados $\mathrm{pH}$, estimativa de proteínas, glicose e sangue oculto. No entanto, a quantificação de proteínas totais do líquor requer um método bioquímico com a utilização de espectrofotômetro, pois a tira reagente é um método semiquantitativo. No atual estudo foi realizada a dosagem de proteínas pelos dois métodos, sendo considerado o método bioquímico para análise estatística.

Também como parte do exame químico, foi realizado o teste qualitativo de proteínas, Teste de Pandy, que detecta o aumento de globulinas. Para a realização, utilizou-se uma gota da amostra em $1 \mathrm{~mL}$ do reativo de Pandy que, apresentando turbidez da solução, foram consideradas amostras positivas e puderam ser classificadas em cruzes $(+,++$ ou +++$)$ pelo grau de turbidez.

As contagens de hemácias e células nucleadas foram realizadas no hemocitômetro padrão (Câmara de Neubauer). Para as contagens de células nucleadas e hemácias foram preenchidas ambas as câmaras do hemocitômetro e todas as células presentes na área da câmara foram contadas, para obtenção de uma contagem total por microlitro.

Como o líquor normalmente apresenta baixa celularidade, há necessidade de concentração destas células através da citocentrifugação, que foi realizada colocando-se de 6 a 8 gotas $(200 \mu \mathrm{L})$ da amostra em um citofunil acoplado a uma lâmina e cetrifugada a $800 \mathrm{rpm}$ por 5 minutos. As preparações de citocentrifugação foram secas ao ar livre e coradas com panótico rápido (um tipo de coloração Romanowski) (Cowell et al., 2007). Na objetiva de imersão de um microscópio óptico, realizou-se a leitura da lâmina preparada, visando à contagem de no mínimo 50 células nucleadas.

Todos os animais receberam a ribavirina (Ribaviron $\mathrm{C}^{\circledR}$ ) por via oral, na dose de $30 \mathrm{mg} / \mathrm{kg}$, a cada 24 horas, durante 15 dias.

A ribavirina, com apresentação de cápsulas de $250 \mathrm{mg}$, foi manipulada de forma estéril e transformada em solução para facilitar o cálculo da dose e administração do medicamento. A diluição foi realizada em solução fisiológica de cloreto de sódio a $0,9 \%$ estéril, na concentração de $40 \mathrm{mg} / \mathrm{mL}$ e armazenada em frascos de vidro estéreis, de coloração âmbar, refrigerada na temperatura de $2^{\circ}$ a $8^{\circ} \mathrm{C}$ e mantida até 30 dias.

O teste de McNemar (Pagano e Gauvreau, 2000) foi utilizado com o procedimento PROC FREQ (SAS Institute, 2009) para comparar a proporção de animais com a patologia liquórica alterada ( $\operatorname{sim}=1$ ou não $=0$ ). O nível de significância foi definido como $\mathrm{P}<0,05$.

\section{Resultados}

Os 10 animais estudados foram positivos para cinomose no teste de imunofluorescência direta.

$\mathrm{Na}$ análise do líquor, antes e após o tratamento, as principais alterações foram: pleocitose, aumento no número de linfócitos acima de $60 \%$, aumento de proteínas acima de $25 \mathrm{mg} / \mathrm{dl}$ e o teste de Pandy negativo (Tabela 1), sendo que estes dados não apresentaram resultados significativos estatisticamente.

No entanto, a taxa de mortalidade ficou em $30 \%$ dos animais com piora clínica progressiva. Outros dois animais não obtiveram melhora aparente, porém não evoluíram na doença neurológica; $50 \%$ da população apresentou redução dos sinais neurolóogicos, principalmente a partir do quinto dia da administração da ribavirina.

Tabela 1: Principais alterações liquóricas dos caninos com cinomose encontradas antes e após a utilização do tratamento antiviral, Botucatu, 2012

\begin{tabular}{cccc}
\hline & \multicolumn{2}{c}{$\begin{array}{c}\text { Número de animais } \\
\text { (percentagem) }\end{array}$} & \\
\cline { 2 - 3 } Alterações & $\begin{array}{c}\text { Antes do } \\
\text { tratamento }\end{array}$ & $\begin{array}{c}\text { Após o } \\
\text { tratamento }\end{array}$ & Valor de p \\
\hline Pleocitose & $8(80 \%)$ & $4(50 \%)$ & 1,000 \\
Proteinorraquia & $7(70 \%)$ & $6(75 \%)$ & 0,480 \\
Linfócitos acima de $60 \%$ & $8(80 \%)$ & $5(62,5 \%)$ & 0,480 \\
Teste de Pandy negativo & $8(80 \%)$ & $6(75 \%)$ & 1,000 \\
\hline
\end{tabular}

Estatística: Teste de Mc Nemar, sendo considerado o nível de significância $p>0,050$ 


\section{Discussão}

Sendo a cinomose uma doença que apresenta elevada morbidade e letalidade (Moro e Vasconcelos, 1998; Gebara et al., 2004), deixando sequelas da fase neurológica, podemos considerar que a ribavirina foi capaz de diminuir a mortalidade dos animais tratados, já que apenas três animais vieram ao óbito e cinco apresentaram melhora clínica aparente.

Atualmente a terapia antiviral com ribavirina em pacientes com hepatite $\mathrm{C}$ tem sobrevida de aproximadamente 55\% (Sung et al., 2011). Assim, o atual estudo foi capaz de evidenciar a eficácia da ribavirina frente ao vírus da cinomose, já que se obtiveram $70 \%$ de sobrevida devido ao tratamento antiviral.

No entanto, alguns fatores podem interferir na ação do antiviral, como Chang e Heel (1981) citam: a cepa e quantidade de vírus, a via de infecção, a idade e sexo dos indivíduos, frequência e via de administração da droga. Como ainda não temos estudos farmacocinéticos da ribavirina em cães, não podemos afirmar se sua eficácia foi prejudicada por algum destes fatores nos cães que vieram ao óbito, ou mesmo na redução do processo inflamatório.

Com relação à biodisponibiliade da ribavirina, sabe-se que 33 a $45 \%$ da droga são absorvidas na administração oral. Porém, sabe-se que no líquor são alcançadas até $70 \%$ da concentração do plasma. É importante ressaltar o alto poder de concentração no eritrócito e que sua meia-vida no plasma é de 24 horas, mas uma pequena quantidade da droga persiste no plasma por mais de 16 dias (Chang e Heel, 1981; Hayden e Douglas, 1990; Grancher et al., 2004). O estudo priorizou estas informações no cálculo da dose, via e formas de administração e, por isso, a utilização da ribavirina no período de 15 dias. Desta forma, tentou-se alcançar a concentração ideal da droga no líquor utilizando-se esta persistência no plasma sanguíneo. Portanto, ainda devemos considerar o estudo farmacocinético da ribavirina específico em cães.

Segundo alguns autores, podem existir complicações imunológicas após a redução do antígeno viral no SNC, devido a um aumento na expressão do complexo de Histocompatibilidade Principal nas células da micróglia, sendo responsável pela desmielinização contínua e infiltração mononuclear perivascular disseminada. Pode estar associada também a uma concentração alta de anticorpos antimielínicos, como uma reação secundária ao processo inflamatório. Como outros fatores imunológicos, como a produção de radicais livres de oxigênio pelos macrófagos no SNC pode levar à destruição de oligodentrócitos e da bainha de mielina (Tipold et al., 1992; Summers et al., 1995; Gebara et al., 2004; Greene e Appel, 2006). Desta forma, o processo inflamatório se perpetua, mantendo as concentrações elevadas de proteína e celularidade no líquor mesmo com a utilização da droga antiviral, neste intervalo de tempo.

\section{Conclusão}

Pela análise do líquor, podemos afirmar que a inflamação causada pelo vírus no sistema nervoso central não diminuiu, mesmo com a utilização do antiviral.

A análise do líquor não foi suficiente para discutir a eficácia da ribavirina "in vivo".

\section{Agradecimentos}

Agradecemos à FUNDUNESP pelo financiamento do estudo e ao Laboratório Biolunis Ltda. por fornecer a ribavirina.

\section{Referências}

CHANG, T. W., HEEL, R. C. Ribavirin and Inosiplex: A Review of their Present Status in Viral Diseases. Drugs, v. 22, n. 2, p. 111128, 1981.

$\mathrm{CHO}, \mathrm{H}$. S.; PARK, N. Y. Detection of canine distemper virus in blood samples by reverse transcription loop-mediated isothermal amplification. Journal of Veterinary Medicine, v. 52, p. 410-413, 2005.

CORRÊA, C. N. M. Cinomose. In: CORRÊA, W. M.; CORRÊA, C. N. M. (Eds.). Enfermidades Infecciosas dos Mamíferos Domésticos. Rio de Janeiro: Medsi, 1992. p. 655-670.

COWELL, R. L.; TYLER, R. D.; MEINKOTH, J. H.; DeNICOLA, D. B. (Ed.) Diagnostic Cytology and Hematology of the Dog and Cat. 3. ed. Canadá: Mosby Elsevier, 2007.

DUCOTÉ J. M.; DEWEY, C. W.; Diagnóstico das Doenças do Sistema Nervoso. In: DEWEY, C. W. Neurologia de Cães e Gatos: guia prático. São Paulo: Roca, 2006. p. 35-58.

ELIA, G.; BELLOLI, C.; CIRONE, F.; LUCENTE, M. S.; CARUSO, M.; MARTELLA, V.; DECARO, N.; BUONAVOGLIA, C.; ORMAS, P. In vitro efficacy of ribavirin against canine distemper virus. Antiviral Research, v. 77, p. 108-113, 2008.

GAMA, F. G. V.; NISHIMORI, C. T.; SOBREIRA, M. R.; SANTANA, A. E. Caracteres físico-químicos e citológicos do líquor de cães em diferentes fases da cinomose. Ciência Rural, v. 35, n. 3, p. 596-601, 2005.
GEBARA, C. M. S.R.; WOSIACKI, S. R.; NEGRÃO, F. J.; ALFIERI, A. A.; ALFIERI, A. F. Lesões histológicas no sistema nervoso central de cães com encefalite e diagnóstico molecular da infecção pelo vírus da cinomose canina. Arquivo Brasileiro de Medicina Veterinária e Zootecnia, v. 56, n. 2, p. 168-174, 2004.

GRANCHER, N.; VERNARD, V.; KEDZIEREWICZ, F.; AMMERLAAN, W.; FINANCE, C.; MULLER, C. P.; FAOU, A. Le. Improved antiviral activity in vitro of ribavirin against measles virus after complexation with cyclodextrins. Antiviral Research, v. 62, n. 3 p. 135-137, 2004. doi:10.1016/j.antiviral.2004.01.003

GREENE, C. E.; APPEL, M. J. Canine Distemper In: GREENE, C. E. (Eds.). Infectious Disease of the Dog and Cat. Philadelphia: Elsevier, 2006. p. 25-41.

HAYDEN, F. G.; DOUGLAS, R. G. JR. Antiviral Agents. In: MANDELL, G. L., DOUGLAS, R. G. JR.; BENNETT, J. E. (Eds.). Principles and Pratice of Infectious Disease. New York: Churchill Livingestone, 1990. p. 370-393.

HEADLEY, S. A.; GRAÇA, D. L. Canine Distemper: epidemiological findings of 250 cases. Brazilian Journal of Veterinary Research and Animal Science, v. 37, p. 136-140, 2000. doi: 10.1590/S141395962000000200009

MORO, L.; VASCONCELLOS, A. C. Patogenia da imunossupressão da cinomose canina. A Hora Veterinária, v. 17, n. 102, p. 53-57, 1998.

PAgANO, M.; GaUVREAU, K. Principles of Biostatistics. Ed. Belmont: Duxbury Press, 2000. 
SAS Institute. 2009. SAS/STAT User's Guide. Version 9.2, SAS Institute Inc., Cary, NC.

SUMMERS, B. A.; CUMMINGS, J. F.; LAHUNTA, A. Inflamatory Disease of the Central Nervous System In: SUMMERS, B. A.; CUMMINGS, J. F.; LAHUNTA, A. Veterinary Neuropathology. St. Louis: Mosby, 1995, p. 95-188.

SUNG, H.; CHANG, M.; SAAB, S. Management of hepatitis C antiviral therapy adverse effects. Curr. Hepatitis Rep., v. 10, p. 3340, 2011. Doi: 10.1007/s11901-010-0078-7

TIPOLD, A.; VANDEVELDE, M.; JAGGY, A. Neurological manifestations of canine distemper virus infection. Journal of Small Animal Pratice, v. 33, n. 10, p. 466-470, 1992.
VANDEVELDE, M.; ZURBRIGGEN, A. The neurobiology of canine distemper virus infection. Veterinary Microbiology, v. 44, n. 2-4, p. 271-280, 1995.

VANDEVELDE, M.; ZURBRIGGEN, A. Demyelination in canine distemper virus infection: a review. Acta Neuropathologica, v. 109, p. 56-68, 2005. Doi: 10.1007/s00401-004-0958-4.

VAN MOLL, P.; ALLDINGER, S.; BAUMGÄRTNER, W.; ADAMI, M. Distemper in wild carnivores: an epidemiological, histological and immunocytochemical study. Veterinary Microbiology, v. 44, p. 193199, 1995. 